\title{
THE URINARY EXCRETION AND THYROID UPTAKE OF IODINE IN RENAL DISEASE ${ }^{1}$
}

\author{
By WILLIAM F. PERRY AND JOHN F. S. HUGHES
}

\begin{abstract}
(From the Department of Physiology and Medical Research, University of Manitoba and De- . partment of Medical Research, Winnipeg General Hospital, Winnipeg, Canada)
\end{abstract}

\author{
(Submitted for publication November 29, 1951; accepted March 10, 1952 )
}

Radioactive iodine has proved itself a most useful tool in the assessment of thyroid function and since its introduction in 1938 by Hertz, Roberts, and Evans (1) a voluminous literature on this subject has developed, much of which has been well summarized by Skanse (2) in his monograph.

Although various workers have noted that there is a delayed excretion of the isotope in renal disease which probably invalidates any measurements of urinary excretion of radio-iodine or calculations derived from such measurements as a means of indirectly assessing thyroid function, relatively little investigation of the effect of renal lesions on the more direct measurements of thyroid function with radio-iodine has been carried out. McConahey, Keating, and Power ( 3 ) have noted an apparently decreased rate of accumulation of radio-iodine by the thyroid gland, a finding generally indicative of depressed thyroid function. It thus seemed of interest to further investigate this problem to see firstly if renal disease in any way invalidates the use of tracer doses of radio-iodine as a diagnostic aid in assessing thyroid function, and secondly, with the aid of the isotope, to study some phases of iodine metabolism and utilization in subjects with renal disorders.

\section{SUBJECTS AND METHODS}

Patients with kidney disease were chosen only when they showed obvious signs of renal failure-elevated blood urea nitrogen, gross albuminuria and poor urinary concentrating power. These subjects are listed in Table I. A control group composed of normal persons or patients not known to have any dysfunction of either kidneys or thyroid is similarly listed in Table II. In both groups special care was taken to select subjects who had not previously had organic iodine compounds, e.g., priodax or lipiodol, and who had not had any inorganic iodine medication for at least two months previously.

1 The subject matter of this paper is part of a thesis submitted by Dr. Hughes to the Faculty of Graduate Studies, University of Manitoba in partial fulfillment of the requirements for the degree M.Sc. (Med.)
Observations were made on the subjects after an overnight fast of at least 14 hours and they continued without food for the first six hours of the experimental period.

The fasting subject was required to void completely, and immediately afterwards was given 100-125 microcuries of carrier free radioactive iodine orally. Two to two and one-half hours later when absorption of the radio-iodide was probably complete, the patient again voided, a blood sample was obtained and the time noted. Counts over the thyroid were then begun and midway through the counting period, a second blood sample was taken and the time noted. An accurately measured time interval of approximately two hours was allowed to elapse whereupon the patient again voided and blood samples and thyroid counts were repeated.

By these procedures it was possible to determine the clearance of radio-iodine from the plasma by the kidneys and the thyroid. A further blood specimen was obtained 26 hours after the administration of the tracer dose.

The quantity of radio-iodine present in the thyroid at any given time was expressed as a percent of the dose given and was determined by direct counts 6 inches above the thyroid isthmus, using a shielded collimated Geiger tube (4) and comparing the counts with similar ones over a standard solution of radio-iodine in a glass container. At least 1,000 counts were obtained in each instance. Background radiation was corrected for by subtracting counts obtained 6 inches over the middle of the thigh. Thyroid counts were made at two, four, 26, 50, and 75 hours after the ingestion of the dose.

Blood samples were collected in heparin or oxalate and the plasma immediately separated. Protein bound iodine estimations were made on one of the specimens, generally the first one taken, using the method of Barker (5), which was also found satisfactory for the determination of urinary iodine. The plasma concentration of $\mathrm{I}^{132}$ was determined on each sample of plasma, using the principles of the method of Barry (6) in which the radioiodine together with a controlled weight of added carrier is precipitated as insoluble palladium iodide and counted. Duplicate $1 \mathrm{ml}$. aliquots of plasma were precipitated with $3 \mathrm{ml}$. 8\% trichloroacetic acid. The samples were centrifuged and $2 \mathrm{ml}$. of supernatant removed; to this was added $1 \mathrm{ml}$. of $1.5 \% \mathrm{KI}$ followed by an excess of palladium chloride. The resulting precipitate of palladium iodide was filtered off by means of a Tracerlab E-8A precipitation apparatus, dried and its radioactivity measured. The urine passed during the clearance period was similarly treated. For each aliquot at least 1,500 counts were scaled in determining the counting rates, which in 
TABLE I

Clinical details of patients with renal disease

\begin{tabular}{|c|c|c|c|c|c|c|}
\hline Cases & Age & B.U.N. & $\underset{\text { creatinine }}{\text { Plasma }}$ & $\begin{array}{l}\text { Creatinine } \\
\text { clearance }\end{array}$ & P.B.I. & Diagnosis \\
\hline $\begin{array}{l}\text { M. W. } \\
\text { F. B. } \\
\text { H. A. } \\
\text { E. M. } \\
\text { M. R. } \\
\text { B. S. } \\
\text { A. H. } \\
\text { H. A. } \\
\text { C. S. } \\
\text { E. P. } \\
\text { E. V. } \\
\text { B. P. }\end{array}$ & $\begin{array}{l}50 \\
56 \\
53 \\
25 \\
37 \\
22 \\
37 \\
75 \\
52 \\
74 \\
74 \\
37\end{array}$ & $\begin{array}{c}m g m . \% \\
38 \\
34 \\
66 \\
23 \\
158 \\
49 \\
23 \\
48 \\
21 \\
34 \\
31 \\
25\end{array}$ & $\begin{array}{c}m g m . \% \\
1.1 \\
1.3 \\
3.9 \\
2.0 \\
9.9 \\
3.9 \\
1.4 \\
2.1 \\
1.1 \\
1.4 \\
1.6 \\
1.2\end{array}$ & $\begin{array}{c}\text { ml./min.* } \\
52.6 \\
56.5 \\
22.0 \\
48.8 \\
7.3 \\
20.6 \\
86.9 \\
24.4 \\
87.0 \\
37.5 \\
30.4 \\
69.3\end{array}$ & $\begin{array}{c}\mu g m . \% \\
7.8 \\
4.7 \\
4.2 \\
4.0 \\
\overline{4.7} \\
\overline{4.2} \\
3.3 \\
4.9 \\
3.7 \\
4.9\end{array}$ & $\begin{array}{l}\text { Kummelstiel-Wilson's disease } \\
\text { Bilateral pyonephrosis } \\
\text { Chronic nephritis } \\
\text { Sub-acute nephritis } \\
\text { Polycystic kidneys } \\
\text { Chronic nephritis } \\
\text { Kummelstiel-Wilson's disease } \\
\text { Nephrosclerosis } \\
\text { Chronic nephritis } \\
\text { Kummelstiel-Wilson's disease } \\
\text { Nephrosclerosis } \\
\text { Kummelstiel-Wilson's disease }\end{array}$ \\
\hline
\end{tabular}

* Standardized to body surface area of $1.73 \mathrm{sq} . \mathrm{m}$.

duplicate samples agreed within $5 \%$. A suitable aliquot of the original dose of $I^{121}$ was subjected to a similar precipitation and its radioactivity measured. This formed the reference standard for the plasma and urine samples. All radioactive measurements were made with Tracerlab TGC-1 Geiger tubes $\left(2 \mathrm{mgm} . / \mathrm{cm}^{2}\right.$ windows) and a Tracerlab 64 scaler. Measurements of urine radioactivity were made until the asymptotic amount had been excreted. From the urine excretion curves one was able to derive certain values described by Keating, Power, Berkson, and Haines (7), namely, the disappearance rate of radioiodine from the blood and the renal and extra-renal disposal rates of the radio-iodine.

Renal clearance of radio-iodine was computed using the conventional formula UV/P. However, as the plasma level of $I^{13}$ falls in an exponential manner with time, a logarithmic mean concentration was calculated using the formula $\frac{P_{1}-P_{2}}{\ln P_{1}-\ln \cdot P_{2}}$ as suggested by Keating and associates (8). Clearance values were standardized to a body surface area of $1.73 \mathrm{sq}$. m. As a measure of the glomeru- lar filtration rate endogenous creatinine clearance for the two hour clearance period was determined. Endogenous creatinine clearance has been shown to follow inulin clearance fairly closely (9) and thus will approximate the glomerular filtration rate. It was also standardized to a body surface area of $1.73 \mathrm{sq} . \mathrm{m}$.

From the glomerular filtration rate and the renal clearance of radio-iodine the percentage of the filtered $\mathrm{I}^{121}$ reabsorbed by the kidney tubules was calculated.

The rate of clearance of $I^{121}$ from the plasma by the thyroid gland was obtained by dividing the percentage of the dose accumulated per minute during the two hour clearance period by the mean plasma concentration (percent dose/ml.) during this period.

The plasma concentration of stable inorganic iodide during the clearance period was measured indirectly, as the direct measurement of physiological amounts of stable iodide in plasma is technically difficult compared with its measurement in urine. The procedure was similar to that of Stanley (10) by which it is assumed that radioactive and stable iodine are handled indiscrimi-

TABLE II

Clinical details of normal subjects and patients without renal disease

\begin{tabular}{|c|c|c|c|c|c|c|}
\hline Cases & Age & B.U.N. & $\underset{\text { creatinine }}{\text { Plasma }}$ & $\begin{array}{l}\text { Creatinine } \\
\text { clearance }\end{array}$ & P.B.I. & Diagnosis \\
\hline $\begin{array}{l}\text { J. J. } \\
\text { H. C. } \\
\text { A. P. } \\
\text { M. N. } \\
\text { A. R. } \\
\text { E. C. } \\
\text { S. C. }\end{array}$ & $\begin{array}{l}51 \\
43 \\
71 \\
46 \\
25 \\
32 \\
37\end{array}$ & $\begin{array}{l}m g m . \% \\
= \\
= \\
\overline{16} \\
12\end{array}$ & $\begin{array}{l}m g m . \% \\
1.1 \\
0.7 \\
1.1 \\
\overline{0.8} \\
1.0 \\
1.1\end{array}$ & $\begin{array}{l}\operatorname{ml.} / \min .^{*} \\
114 \\
108 \\
83.3 \\
\overline{114} \\
95 \\
107\end{array}$ & $\begin{array}{l}{ }^{\mu g m . \%} \\
\overline{-} \\
\overline{5.0} \\
5.0 \\
5.2\end{array}$ & $\begin{array}{l}\text { Spontaneous pneumothorax } \\
\text { Fractured femur } \\
\text { Fractured humerus } \\
\text { Atopic dermatitis } \\
\text { Normal } \\
\text { Normal } \\
\text { Methyl hydrate poisoning-no kid- }\end{array}$ \\
\hline $\begin{array}{l}\text { C. N. } \\
\text { W. } \\
\text { J. } \mathbf{P} . \\
\text { G. F. } \\
\text { D. S. }\end{array}$ & $\begin{array}{l}26 \\
26 \\
30 \\
21 \\
21\end{array}$ & E & $\begin{array}{l}0.7 \\
0.9 \\
0.9 \\
0.9 \\
1.1\end{array}$ & $\begin{array}{l}125 \\
124 \\
124 \\
146 \\
118\end{array}$ & $\begin{array}{l}6.2 \\
4.5 \\
4.0 \\
4.2 \\
3.5\end{array}$ & $\begin{array}{l}\text { Normal } \\
\text { Thumb injury } \\
\text { Pneumonia } \\
\text { Convalescent typhoid } \\
\text { Normal }\end{array}$ \\
\hline
\end{tabular}

* Standardized to body surface area of 1.73 sq. m. 
TABLE III

The renal clearance and urinary excretion of $\Gamma^{131 *}$

\begin{tabular}{|c|c|c|c|c|c|c|c|c|}
\hline Subjects & \multicolumn{2}{|c|}{ Renal clearance } & \multicolumn{2}{|c|}{48 hour excretion } & \multicolumn{2}{|c|}{ Renal excretion rate } & \multicolumn{2}{|c|}{ Extra-renal disposal rate } \\
\hline $\begin{array}{l}\text { Controls } \\
\text { Renal disease }\end{array}$ & $\begin{array}{l}\text { no. } \\
11 \\
11\end{array}$ & $\begin{array}{r}\text { ml. } / \min . \\
31.4 \pm 2.0 \\
5.5 \pm 1.2\end{array}$ & $\begin{array}{c}n o . \\
9 \\
8\end{array}$ & $\begin{array}{c}\% \text { dose } \\
78.3 \pm 3.5 \\
41.7 \pm 7.5\end{array}$ & $\begin{array}{c}n o . \\
9 \\
7\end{array}$ & $\begin{array}{c}\text { \%/hour } \\
10.2 \pm 1.0 \\
1.6 \pm 0.3\end{array}$ & $\begin{array}{c}\text { no. } \\
9 \\
7\end{array}$ & $\begin{array}{c}\% / \text { hour } \\
3.6 \pm 0.8 \\
1.1 \pm 0.3\end{array}$ \\
\hline$P$ values & \multicolumn{2}{|c|}{$<.01$} & \multicolumn{2}{|c|}{$<.01$} & \multicolumn{2}{|c|}{$<.01$} & \multicolumn{2}{|c|}{$<.01$} \\
\hline
\end{tabular}

* Mean values \pm standard error.

nately by any organ. Thus at any given time the ratio of each in urine and plasma will be the same; and thus knowing the urinary concentrations of $I^{127}$ and $I^{13}$, and from the determination of the mean plasma concentration of $I^{181}$, the plasma level of $\mathrm{I}^{127}$ is readily calculated. Likewise by assuming the thyroid is similarly nonselective towards iodine isotopes, the amount of iodine picked up per unit time by the gland can be calculated from the known urine or plasma concentrations of the two isotopes and the known rate of uptake of $\mathrm{I}^{131}$ by the gland. By this means the plasma level of $\mathrm{I}^{12}$, the hourly uptake of $\mathrm{I}^{127}$ by the thyroid, and the hourly filtration and resorption of $\mathrm{I}^{122}$ by the kidneys during the two hour fasting clearance period were calculated. It has been shown that the distribution of $\mathrm{I}^{131}$ throughout the body requires some six hours (11). However, this need not invalidate the calculation so long as the plasma reaching the kidney and thyroid have the same levels of radio-iodine and the plasma level is falling in an exponential manner. The above calculations assume that all the urinary iodine is in the form of iodide. It has recently been shown by Rall (12) that organic iodine compounds may be excreted in urine, but in the euthyroid individual they comprise a very small portion of the total urine iodine and hence the resultant error in the calculated plasma iodide level should be small, and it is presumed in this study that the urine of individuals with renal disease likewise does not differ in this respect.

The percentage resorption of chloride and sodium loads by the renal tubules was estimated on some subjects. Sodium was measured by flame photometry and chlorides by the method of Shales and Shales (13) in plasma, and by the Volhard-Arnold method in urine (14).

\section{RESULTS}

\section{(A) Results on the urinary excretion of radio- iodine in kidney disease}

The renal clearance of radio-iodide by $11 \mathrm{pa}-$ tients with kidney disease and by 11 control subjects is shown in Table III. Also shown in this table are the 48 hour urinary excretions of the isotope and the calculated renal excretion rates and extra-renal disposal rates of radio-iodine, these latter two values being derived according to the principles of Keating and co-workers (7). All values were markedly lower in the patients with kidney disease including the calculated extra-renal disposal rate of $\mathrm{I}^{131}$. This latter value approached the levels found in hypothyroidism and if assessment were made on this basis only it might be concluded that the thyroid glands of a person with renal dysfunction were underactive.

The level of the isotope in the plasma 26 hours after administration of the dose is shown in Table IV and further illustrates that there is considerable retention of radio-iodine. The mechanism of the poor renal clearance is demonstrated by other values presented in this table which indicate that not only fasting level of stable iodide $\mathrm{I}^{127}$ in the plasma is considerably greater than the level in the control subjects, but in addition the

TABLE IV

The renal filtration and reabsorption of $I^{131}$ and $I^{197}$ under fasting conditions. The 26 hour plasma level of $I^{131}$; the fasting $I^{127}$ plasma level*

\begin{tabular}{|c|c|c|c|c|c|c|c|c|c|c|c|c|}
\hline Subjects & No. & $\begin{array}{l}\text { \% dose } \\
\text { filtered } \\
\text { (per } \mathrm{hr} . / \\
1.73 \mathrm{m.})\end{array}$ & No. & 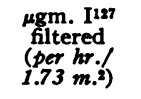 & No. & $\begin{array}{l}\text { \% reabsorp- } \\
\text { tion of } \\
\text { filtered I's1 }\end{array}$ & No. & $\begin{array}{c}\text { Reabsorption } \\
\text { of I127 } \\
(\mu \mathrm{gm} . / \mathrm{hr} . / \\
1.73 \mathrm{m.2})\end{array}$ & No. & $\begin{array}{l}26 \text { hour } \\
\text { plasma I'11 } \\
(\% \text { dose/ } \\
100 \mathrm{ml} .)\end{array}$ & No. & $\begin{array}{c}\text { Plasma I197 } \\
(10 \mathrm{gm} . / \mathrm{ml}) \\
100 \mathrm{~m}\end{array}$ \\
\hline $\begin{array}{l}\text { Controls } \\
\text { Renal disease }\end{array}$ & $\begin{array}{l}11 \\
11\end{array}$ & $\begin{array}{l}24.2 \pm 2.4 \\
12.1 \pm 2.9\end{array}$ & $\begin{array}{l}7 \\
6\end{array}$ & $\begin{array}{l}13.7 \pm 5.8 \\
28.2 \pm 8.2\end{array}$ & $\begin{array}{l}11 \\
11\end{array}$ & $\begin{array}{l}72.9 \pm 1.5 \\
85.9 \pm 3.1\end{array}$ & $\begin{array}{l}7 \\
6\end{array}$ & $\begin{array}{r}9.9 \pm 6.0 \\
23.2 \pm 7.3\end{array}$ & $\begin{array}{l}6 \\
6\end{array}$ & $\begin{array}{l}0.027 \pm .006 \\
0.210 \pm .012\end{array}$ & $\begin{array}{l}7 \\
6\end{array}$ & $\begin{array}{l}0.17 \pm .005 \\
2.20 \pm 0.50\end{array}$ \\
\hline$P$ values & & $<.01$ & & $<.01$ & & $<.01$ & & $<.01$ & & $<.01$ & & $<.01$ \\
\hline
\end{tabular}

* Mean values \pm standard error. 
TABLE V

Percentage reabsorption of tubular loads of chloride and sodium under fasting conditions

\begin{tabular}{c|c|c|c|c|c}
\hline \hline \multicolumn{3}{c|}{ Controls } & \multicolumn{3}{c}{ Renal disease } \\
\hline Case & $\mathrm{Cl}$ & $\mathrm{Na}$ & Case & $\mathrm{Cl}$ & $\mathrm{Na}$ \\
\hline A. R. & 99.8 & 99.1 & E. P. & 98.6 & 98.2 \\
G. F. & 99.1 & 98.4 & E. V. & 98.2 & 98.7 \\
D. S. & 99.7 & 99.5 & & &
\end{tabular}

defective clearance of radio-iodide from the plasma is due not only to a decreased rate of glomerular filtration but also because the tubular reabsorption of the filtered $\mathrm{I}^{\mathbf{1 3 1}}$ is significantly higher in those with renal disease. Despite depressed glomerular filtration rates, when the amounts of filtered and reabsorbed stable iodide $\mathrm{I}^{127}$ were calculated, it was found that under the fasting conditions of the experimental period considerable more iodide was filtered per unit time by the diseased subjects. This was due to the high plasma levels of iodide

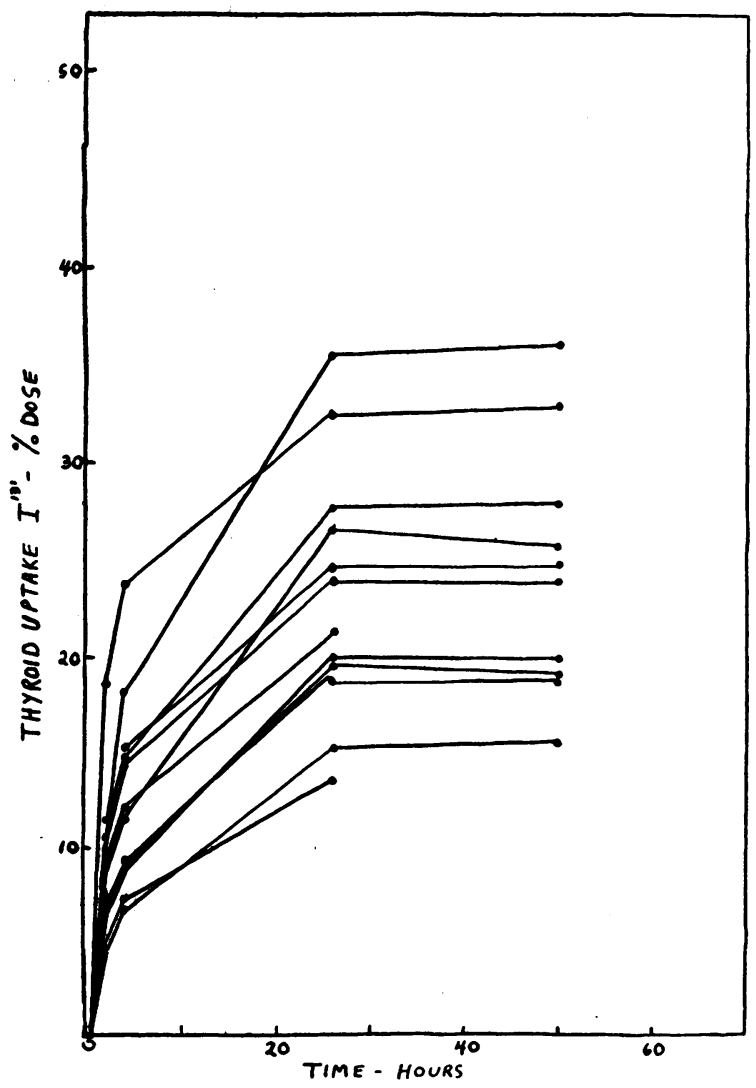

Fig. 1. Thyroid Uptake of Radio-Iodine by Control SUBJECTS

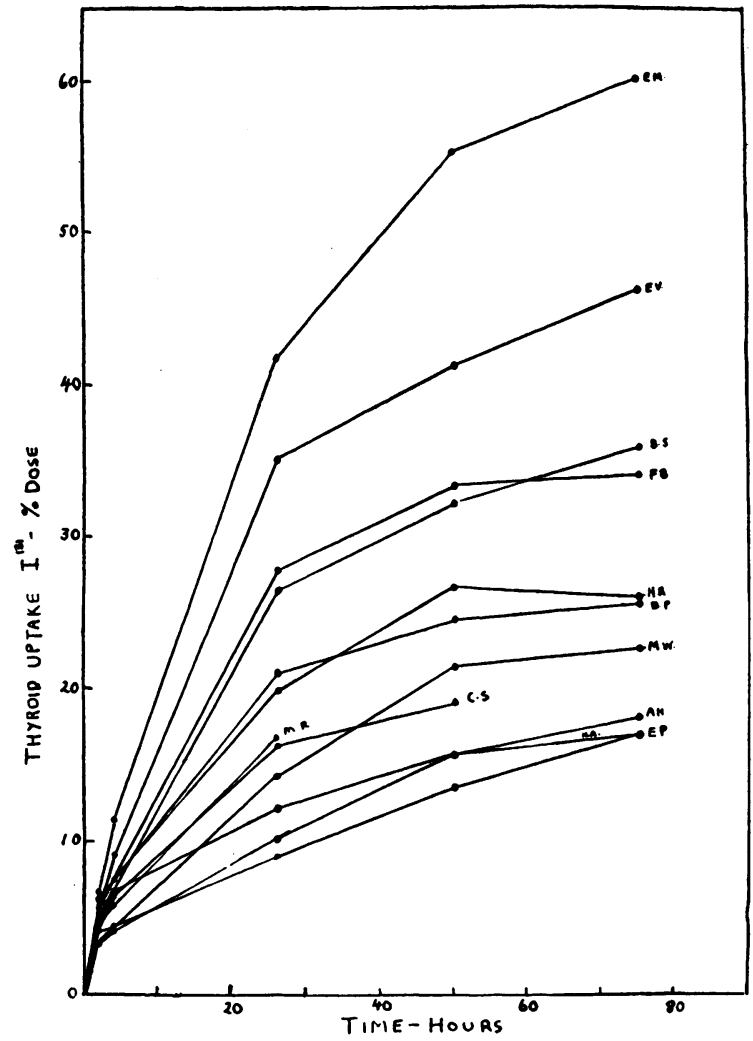

Fig. 2. Thyroid Uptake of Radio-Iodine by Subjects with Renal Disease

$\mathrm{I}^{127}$. As a higher percentage of filtered $\mathrm{I}^{131}$ was reabsorbed by the tubules, consequently much more iodide $\mathrm{I}^{127}$ was also being reabsorbed by the sick subjects.

It was noted in the few subjects in which it was done that the percentage tubular reabsorption of filtered sodium and chloride was if anything somewhat less in the patients with kidney disease. This is in marked contrast to their handling of the other halogen iodide. These figures are set forth in Table V.

\section{(B) Results on the thyroid uptake of radio-iodine in kidney disease}

Most of the control subjects had taken up their maximum amount of $\mathrm{I}^{131}$ into their thyroids by 26 hours after the dose. This is illustrated in Figure 1. In a few cases there was a further small increase during the following 24 hours. This never amounted to more than $1.4 \%$ of the dose. The results obtained in 12 patients with kidney diseases, shown in Figure 2, were markedly different. It 
TABLE VI

The thyroid clearance and thyroid uptake of $I^{131}$; the fasting plasma $I^{127}$ level and thyroid uptake of $I^{127 *}$

\begin{tabular}{|c|c|c|c|c|c|c|c|c|}
\hline Subjects & \multicolumn{2}{|c|}{ Thyroid clearance } & \multicolumn{2}{|c|}{ Thyroid uptake I'13 } & \multicolumn{2}{|c|}{ Plasma I127 } & \multicolumn{2}{|c|}{ Thyroid uptake I'27 } \\
\hline $\begin{array}{l}\text { Controls } \\
\text { Renal disease }\end{array}$ & $\begin{array}{l}\text { no. } \\
12 \\
11\end{array}$ & \begin{tabular}{r}
\multicolumn{1}{c}{ ml. $/ \min }$. \\
$12.1 \pm 2.5$ \\
$4.3 \pm 1.5$
\end{tabular} & $\begin{array}{l}\text { no. } \\
11 \\
10\end{array}$ & $\begin{array}{c}\% / \text { hour } \\
4.2 \pm 0.6 \\
1.8 \pm 0.2\end{array}$ & $\begin{array}{c}n o . \\
7 \\
6\end{array}$ & $\begin{array}{l}\mu \mathrm{gm} . / 100 \mathrm{ml} . \\
0.17 \pm .005 \\
2.20 \pm 0.50\end{array}$ & $\begin{array}{c}\text { no. } \\
7 \\
6\end{array}$ & $\begin{array}{c}\mu g m . / h r . \\
1.08 \pm 0.23 \\
2.9 \pm 0.80\end{array}$ \\
\hline$P$ values & \multicolumn{2}{|c|}{$<.01$} & \multicolumn{2}{|c|}{$<.01$} & \multicolumn{2}{|c|}{$<.01$} & \multicolumn{2}{|c|}{$<.05$} \\
\hline
\end{tabular}

* Mean values \pm standard error.

will be seen that while at 26 hours after the dose the thyroid uptake was not greatly dissimilar from the controls, it was in all cases followed by further increases. One case (E. M.) with chronic nephritis showed a rather odd curve for $\mathrm{I}^{131}$ thyroid uptake with a maximum uptake reached at 75 hours of some $60 \%$ of the dose. This patient was clinically euthyroid and had protein bound plasma iodine level within normal limits. Values derived from this patient were not included in the series.

Corresponding with the flattened thyroid uptake curves it will be noted in the patients with renal disease that the mean rate of thyroid clearance of plasma of $I^{181}$ and also the rate of uptake of $\mathrm{I}^{131}$ by the thyroid are considerably less than these same rates in control subjects. These values are shown in Table VI. On the basis of these figures as well as from the extra-renal disposal rates reported above one might conclude that the thyroids of persons with renal disorders were hypofunctioning. However, as is also shown in Table VI, when the actual quantities of stable iodide $\mathrm{I}^{127}$ entering the gland are considered, the mean rate of uptake of $\mathrm{I}^{127}$ by seven control subjects was found to be $1.08 \mu \mathrm{gm}$. per hour under fasting conditions while in six persons with renal dysfunction it was found to be $2.9 \mu \mathrm{gm}$. per hour, a highly significant difference. It would thus appear that the thyroid gland in kidney disease is not hypoactive and actually more iodine per unit time is entering the gland under fasting conditions. As all of the subjects were clinically euthyroid and none had the elevated levels of protein bound plasma iodine characteristic of hyperthyroidism, it would appear that despite the enhanced uptake of iodine into the thyroid, there was no increased production of hormone by the gland.

\section{DISCUSSION}

Since there was much evidence of kidney parenchyma damage including elevated plasma creatinine levels in the subjects with renal disease it is not surprising that decreased renal clearance rates for radio-iodine and elevated plasma levels at 26 hours were found.

It has been shown by Riggs that iodide clearance rates in normal dogs can be greatly decreased by low sodium chloride intake (15). Of the subjects with kidney disease here studied, seven were on low salt intake, but three were on normal diets and one on normal diet plus $2 \mathrm{gm}$. extra salt per day and these four show an average radio-iodide clearance of $4.6 \mathrm{ml} . / \mathrm{min}$., a value which is somewhat below that of the whole group. Thus although a low sodium chloride intake may bring about a decreased clearance of iodide from the blood, the main cause of the decreased rate in the subjects with renal disease was not this factor but more probably the glomerular and tubular pathology.

The glomerular filtration rate as measured by the endogenous creatinine clearance was found to be decreased. This resulted in a decreased filtration of radio-iodide and consequently a considerable retention of the isotope due to the glomerular damage. However, the retention of $I^{131}$ was not entirely due to poor filtration for there was also increased tubular reabsorption of the filtered radio-iodide. When the quantities of stable iodide involved were calculated, it was shown that despite depressed glomerular function actually more iodine was being filtered per hour than by normal subjects and of the amount filtered, a greater portion was being reabsorbed by the tubules.

A dissimilarity of tubular function in respect to sodium and chloride on the one hand and iodide on the other has appeared in the present study. 
The percentage of resorption of filtered iodide has been estimated to be $73 \%$ by Smith (16). Results in the present study using physiological amounts of iodide labelled with the $\mathrm{I}^{131}$ agree well with this figure. It is remarkable that chloride which is chemically similar to iodide is resorbed by the tubules in percentage amounts similar to those noted for sodium, namely $98-99 \%$ of the tubular load. It has recently been shown by Platt (17) that although patients with renal failure filter less sodium than normal, they resorb a smaller percentage of the tubular load. This was noted also for sodium and chloride in two patients in whom it was examined in the present series. It is therefore interesting that in patients with renal failure there is an increase in the tubular reabsorption of both $I^{131}$ and $I^{127}$ but a fall in the amount of filtered sodium and chloride reabsorbed.

Platt (17) found the degree of reduction in tubular reabsorption of sodium by patients with renal disease was directly related to the amount of decrease in glomerular filtration, thus maintaining a normal plasma level of sodium. In the present series neither a correlation between filtration rate and the degree of iodide resorption nor a maintenance of normal plasma iodide levels was noted.

Since urinary excretion of $\mathrm{I}^{131}$ is much lower than in the control subjects, erroneous interpretations as to thyroid function will be made from urinary excretion values for radio-iodine in kidney disease; likewise misleading results will be obtained from any figures derived originally from urinary excretion data such as the "extra-renal disposal rate" and the "thyroid accumulation rate" of Keating and associates (7).

The observation that the thyroids of patients with kidney disease continued to take up radio-iodine after 26 hours, in contrast to those of normal individuals, is most likely due to the fact that such thyroids are presented with higher plasma levels for longer periods of time. In the patients with kidney disease who, as noted, were clinically euthyroid and had normal levels of protein bound iodine in the plasma, there was a significant decrease in the rate of clearance of radio-iodine from the plasma by the gland. This could be due to either decreased activity of the gland or to dilution of the isotopic iodine with the high plasma levels of stable iodine or to both. In six patients in whom it was indirectly measured, the fasting plasma $I^{127}$ level was on the average over 10 times higher than in the control subjects, therefore considerable dilution of the $I^{131}$ by the stable isotope occurred, thus explaining in part the decreased uptake of $\mathrm{I}^{131}$. As regards the possibility of a decreased avidity for iodine of the thyroid glands of subjects with renal disease, on calculating the actual hourly uptake of $I^{127}$ by the glands, it was shown that the amount of iodide entering the gland per hour was actually higher than in the control subjects. As the patients were clinically euthyroid with normal levels of protein bound plasma iodine, it would seem that hormone formation was not increased. The increased entry of iodide molecules cannot be explained on the basis of an increased accumulation, for the capacity of the gland to hold iodide cannot be infinite. It must therefore be assumed that any increased uptake of inorganic iodine is balanced by an increased loss. This implies an increased rate of exchange between the inorganic iodine of the gland and of the plasma, the precise condition which would be expected in the presence of higher iodide concentrations in two tissues in equilibrium with each other. That there exists a dynamic equilibrium between the iodide of plasma and that of thyroid over a wide range of plasma iodide concentrations has been shown by Vanderlaan and Vanderlaan (18).

Despite the diminished clearance of $I^{131}$ from the plasma and the decreased rate of accumulation of $I^{131}$ by the thyroid, it was noted that the 26 hour thyroid uptake, though lower than similar determinations on control subjects, was not greatly so. It would seem that two opposing factors are at work-a dilution factor due to elevated stable iodine plasma levels which lowers the amount of the radioactive isotope entering the gland, and a retention factor which presents the thyroid with higher levels of $\mathrm{I}^{131}$ for a longer time.

In 11 patients the 26 hour uptake of radio-iodide was within normal limits except in one elderly man where it was quite low. It has been noted, however, by Perlmutter and Riggs (19) that low uptakes of radio-iodide are common in the aged. It would seem therefore that where the question of thyroid assessment comes up in subjects with renal disease and an isolated procedure is used, the 24-26 hour in vivo measurement of thyroid uptake of $\mathrm{I}^{131}$ gives reasonably accurate 
information. This is in marked contrast to urinary excretion data or thyroid clearance or accumulation rates of $\mathrm{I}^{131}$ which, if carried out on patients with renal failure, can give a quite false picture of thyroid function.

\section{SUMMARY}

The urinary excretion and thyroid uptake of radioactive and stable iodide under fasting conditions were studied in a group of patients with renal disease and compared with similar values in a group of control subjects.

It was found that there was a low rate of excretion and a depressed renal clearance of iodine isotopes but in the patients with renal disease a greater proportion of the tubular load was reabsorbed. This was in contrast to the tubular handling of another halogen ion, chloride.

The rate of accumulation of radio-iodide by the thyroid gland was depressed as was also the "extra-renal disposal rate" of iodine calculated from urinary excretion data. Low values were also found for plasma clearance of radio-iodide by the thyroid gland. This was ascribed in part to a dilution of the radioactive isotope by retained stable isotope of dietary origin. When the amounts of stable iodide ( $\mathrm{I}^{127}$ ) involved were computed it was found that actually more iodide was entering the thyroid per unit time than was the case in the control subjects. As the subjects were euthyroid and had normal levels of protein bound iodine in the plasma it was concluded that the increased uptake of iodide by the gland did not lead to an increased production of thyroid hormone.

\section{ACKNOWLEDGMENTS}

The work reported in this paper is part of a project supported by a grant from the National Research Council of Canada. The cooperation of the staff physicians of the Winnipeg General Hospital, in particular Dr. J. P. Gemmell, is gratefully acknowledged; also the technical assistance of Miss M. Hammett and Mrs. H. Yeomans.

\section{REFERENCES}

1. Hertz, S., Roberts, R., and Evans, R. D., Radioactive iodine as an indicator in the study of thyroid physiology. Proc. Soc. Exper. Biol. \& Med., 1938, 38, 510.
2. Skanse, B., Radioactive iodine in the diagnosis of thyroid disease. Acta Med. Scandinav., 1949, 136, Supp. 235.

3. McConahey, W. M., Keating, F. R., Jr., and Power, M. H., An estimation of the renal and extrarenal clearance of radioiodide in man. J. Clin. Invest., 1951, 30, 778.

4. Ansell, G., and Rotblat, J., Radioactive iodine as a diagnostic aid for intrathoracic goitre. Brit. J. Radiol., 1948, 21, 552.

5. Barker, S. B., Determination of protein bound iodine. J. Biol. Chem., 1948, 173, 715.

6. Barry, M. C., A method for the measurement of radioiodine in biological materials. J. Biol. Chem., 1948, 175, 179.

7. Keating, F. R., Jr., Power, M. H., Berkson, J., and Haines, S. F., The urinary excretion of radioiodine in various thyroid states. J. Clin. Invest., 1947, 26, 1138.

8. Keating, F. R., Jr., Wang, J. C., Luellen, T. J., Williams, M. M. D., Power, M. H., and McConahey, W. M., The measurement of the iodine-accumulating function of the human thyroid gland. J. Clin. Invest., 1949, 28, 217.

9. Brod, J., and Sirota, J. H., The renal clearance of endogenous "creatinine" in man. J. Clin. Invest., 1948, 27, 645.

10. Stanley, M. M., The direct estimation of the rate of thyroid hormone formation in man. The effect of iodide ion on thyroid iodine utilization. J. Clin. Endocrinol., 1949, 9, 941.

11. Myant, N. B., Corbett, B. D., Honour, A. J., and Pochin, E. E., Distribution of radioiodide in man. Clin. Sc., 1950, 9, 405.

12. Rall, J. E., Iodine compounds in the blood and urine of man. J. Clin. Endocrinol., 1950, 10, 996.

13. Shales, O., and Shales, S. S., A simple and accurate method for the determination of chloride in biological fluids. J. Biol. Chem., 1941, 140, 879.

14. Hawke, P. B., Oser, B. L., and Summerson, W. H., Practical Physiological Chemistry. Blakiston Co., Philadelphia, 1947, 12th ed.

15. Riggs, D. S., Renal clearance of iodide in the dog. Federation Proc., 1949, 8, 328.

16. Smith, H. W., Lectures on the Kidney. Univ. Kansas, Lawrence, Kans., 1943.

17. Platt, R., Sodium and potassium excretion of chronic renal failure. Clin. Sc., 1950, 9, 367.

18. Vanderlaan, J. E., and Vanderlaan, W. P., The iodide concentrating mechanism of the rat thyroid and its inhibition by thiocyanate. Endocrinology, 1947, 40, 403.

19. Perlmutter, M., and Riggs, D. S., Thyroid collection of radioactive iodide and serum protein-bound iodine concentration in senescence, hyperthyroidism and hypothyroidism. J. Clin. Endocrinol., 1949, 9, 430 . 